\title{
Malignant hypertensive retinopathy as a presenting sign of an occult dead fetus
}

This article was published in the following Dove Press journal:

Clinical Ophthalmology

3 June 2015

Number of times this article has been viewed

Joana Araújo'

João Tavares-Ferreira'

Susana Penas ${ }^{1,2}$

Luís Figueira ${ }^{1,3}$

Flávio Prézia Paiva'

Fernando Falcão-Reis ${ }^{1,2}$

'Ophthalmology Department, São João Hospital, ${ }^{2}$ Department of Sense Organs, ${ }^{3}$ Department of Pharmacology and Therapeutics, Faculty of Medicine, University of Porto, Porto, Portugal

Correspondence: Joana Araújo Hospital de São João, Serviço de Oftalmologia, Avenida Prof Hernâni Monteiro, 4202, 45I Porto, Portugal

Email jrodriaraujo@gmail.com
Abstract: We report one case of malignant hypertensive retinopathy as a presenting sign of fetal death in utero. Ophthalmic examination (including intravenous fluorescein angiography and optical coherence tomography) and obstetric and systemic evaluation were performed, providing a multidisciplinary approach. A 33-year-old overweight woman (body mass index $47 \mathrm{~kg} / \mathrm{m}^{2}$ ) with no systemic or ocular known disease was admitted to our emergency department with a one-week history of bilateral vision loss and no systemic complaints. On examination, best corrected visual acuity was $1 / 10$ in the right eye and 1/10 in the left eye. Anterior segment examination of both eyes was unremarkable. Ophthalmoscopic fundus findings included bilateral optic disc edema, diffuse cotton wool spots, intraretinal exudates, retinal hemorrhages, and multiple serous retinal detachments involving both maculae. Physical examination revealed a blood pressure of 220/ $110 \mathrm{mmHg}$. Further systemic workup revealed a previously unknown 35-week pregnancy with a dead fetus. An emergency cesarean section was performed. Pre-eclampsia is a life-threatening disorder for both mother and fetus. This case highlights the need to rule out pre-eclampsia in all women of childbearing age presenting with ocular signs of malignant hypertension, even without external signs of pregnancy.

Keywords: hypertensive retinopathy, pre-eclampsia, vision loss

\section{Introduction}

Pre-eclampsia complicates $2 \%-8 \%$ of pregnancies, and remains a leading cause of maternal and perinatal morbidity and mortality. ${ }^{1,2}$ It is a pregnancy-specific disease generally defined as new hypertension $(>140 \mathrm{mmHg}$ systolic or $>90 \mathrm{mmHg}$ diastolic blood pressure $)^{3}$ and substantial proteinuria ( $\geq 300 \mathrm{mg}$ in 24 hours) at or after 20 weeks' gestation. ${ }^{4}$ However, the precise definition of this syndrome and the criteria to differentiate mild from severe disease are still being debated. ${ }^{3,5}$ Several clinical and laboratory parameters have classically been used for defining the severity of pre-eclampsia. ${ }^{6}$ Current determination of more severe cases depends mostly on pressure levels and proteinuria, and also the clinical presentation, namely the presence of symptoms such as headache, epigastric pain, and visual disturbances. This systemic disorder can affect almost every organ. Although the cause of pre-eclampsia remains largely unknown, it is characterized by vasospasm and endothelial activation. ${ }^{7}$

The visual system may be affected in $30 \%-100 \%$ of patients with pre-eclampsia. ${ }^{2,8}$ Blurred vision, although rare, is the most common symptom. Other signs such as photophobia, visual spots and diplopia may be observed, and are usually attributed to posterior cerebral artery vasospasm with ischemia, or to cerebral edema in the occipital area. Although retina and its vasculature are more usually affected, the conjunctiva, choroid, the optic nerve and visual cortex may be also affected in pre-eclampsia. ${ }^{7}$ 
The most prominent finding is terminal arteriolar vasospasm, associated with the development of systemic hypertension. ${ }^{\text {? }}$

We herein report a case of severe pre-eclampsia with bilateral vision loss as the presenting symptom, in a woman with an unknown pregnancy.

\section{Case report}

A 33-year-old woman with morbid obesity (body mass index $47 \mathrm{~kg} / \mathrm{m}^{2}$; mean value approximately $25 \mathrm{~kg} / \mathrm{m}^{2}$ for the agematched and sex-matched population ${ }^{9}$ ), without a history of systemic or ocular disease, presented with a one-week history of bilateral vision loss and no systemic complaints. On examination, best corrected visual acuity was $1 / 10$ in the right eye and 1/10 in the left eye. Anterior segment examination of both eyes was normal. Ophthalmoscopic fundus examination (with noncontact slit-lamp lens) revealed bilateral optic disc edema, cotton wool spots, intraretinal exudates, retinal hemorrhages, macular edema, and serous retinal detachments that were inferior to the optic disc and without macular involvement. Blood pressure was 220/110 $\mathrm{mmHg}$. The patient was transferred to the intensive care unit for therapeutic management of hypertension and systemic workup. Laboratory examinations showed thrombocytopenia $\left(67 \times 10^{9} / \mathrm{L}\right)$ and elevated beta-human chorionic gonadotrophin $(6,000 \mathrm{mUI} / \mathrm{mL})$, with no other relevant findings. Ultrasonography revealed a previously unknown pregnancy with a dead fetus. An emergency cesarean section was preferred, considering the surgical risk. Tensional control was achieved post partum. Ophthalmologic fundus examination 12 hours after delivery had similar results, ie, bilateral optic disc edema, narrowing and irregularity of the retinal arteries, with arteriovenous nicking, diffuse cotton wool spots, intraretinal and subretinal exudates, and multiple superficial and deep retinal hemorrhages (Figure 1).

Fluorescein angiogram 12 hours post partum revealed delayed perfusion of the choriocapillaris in both eyes. The posterior pole and peripheral retina presented multiple capillary dilations, focal venous beading, capillary nonperfusion areas, retinal hemorrhages, and late leakage in the optic disc. Multiple areas of focal choroidal ischemia (Elschnig's spots) were seen (Figure 2A-D). Optical coherence tomography 12 hours post partum showed retinal edema, retinal serous detachments presenting with a hyperreflective posterior surface of the detached retina, subretinal hyperreflective lesions corresponding to subretinal exudates, and a thickened peripapillary retinal nerve fiber layer corresponding to optic disc edema (Figure 3A-D). Follow-up examination 6 months after the acute phase revealed complete resolution of previous serous detachments, diffuse arteriolar constriction, and multiple yellowish subretinal discoloration spots (Figure 4A and B).

\section{Discussion}

Pre-eclampsia is a life-threatening disorder for both the mother and fetus, and complicates $2 \%-8 \% \%^{1,2}$ of all pregnancies. It occurs from 20 weeks of gestation up to 6 weeks post partum. It is classified as hypertension developing after 20 weeks of gestation and the coexistence of one or more of the following new-onset conditions: proteinuria, other maternal organ dysfunction (renal insufficiency, liver involvement,

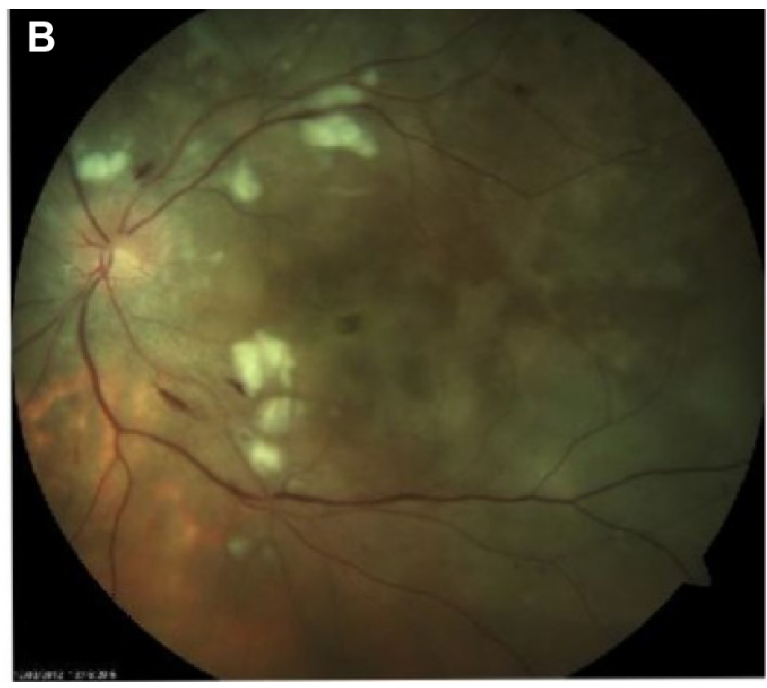

Figure I Retinography 12 hours post partum.

Notes: Bilateral optic disc edema, narrowing, and irregularity of retinal arteries with arteriovenous nicking, diffuse cotton wool spots, intraretinal and subretinal transudates, and multiple superficial and deep retinal hemorrhages. (A) right eye; (B) left eye. 

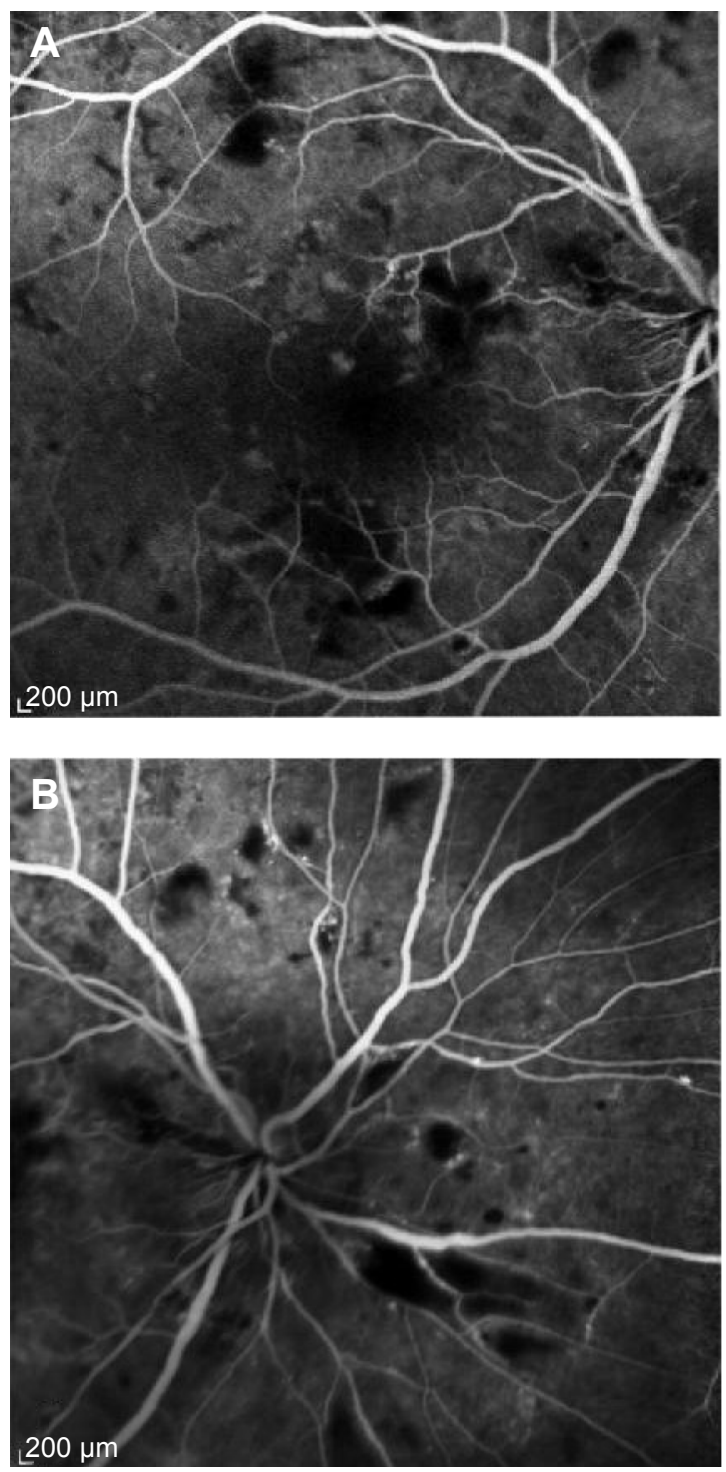

Figure 2 Fluorescein angiogram in early and late phases 12 hours post partum.

Notes: Fluorescein angiogram revealed delayed perfusion of the choriocapillaris in both eyes. The posterior pole and peripheral retina presented multiple capillary dilations, focal venous bleeding, capillary nonperfusion areas, retinal hemorrhages, and late leakage in the optic disc. Multiple areas of focal choroidal ischemia (Elschnig's spots). (A) and (B) right eye; (C) and (D) left eye.

neurologic complications, hematologic complications) or uteroplacental dysfunction (fetal growth restriction). ${ }^{3}$ The commonest ocular finding is severe arteriolar spasm, evidenced by either segmental or generalized constriction of the retinal arterioles, reported in $70 \%$ of cases. ${ }^{10}$ Retinal hemorrhages, edema, and cotton wool spots secondary to arteriolar damage may follow. The severity of retinal arteriolar changes is more closely related to the degree of underlying vasospasm, which may or may not be associated with the blood pressure level. Schultz and O'Brien described the fundus appearance of 47 patients with pre-eclampsia. ${ }^{11}$ Hemorrhages, cotton wool spots, and exudates were seen in 12 patients, all of whom had blood pressure ranging from $170 / 115 \mathrm{mmHg}$ to $230 / 160 \mathrm{mmHg}$. Serous retinal detachment is an unusual but well documented
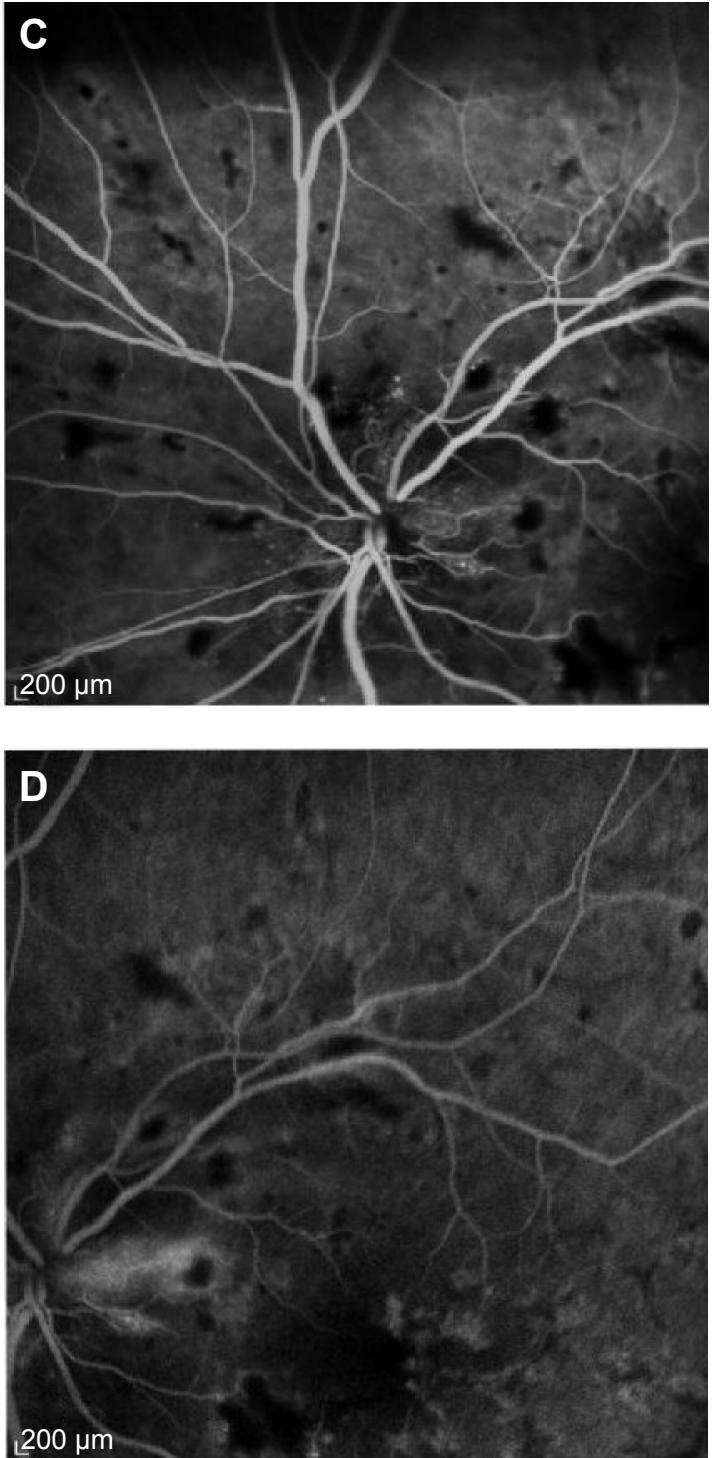

cause of visual loss in pre-eclampsia. It affects $1 \%-2 \%$ of patients in its most severe form and is slightly more common in the eclamptic patient. ${ }^{7}$ It may be present either before or after delivery. Bilateral, bullous, and serous detachments are usually present, and are frequently observed in the absence of significant retinal vascular abnormalities. It is believed that choroidal ischemia secondary to intensive arteriolar vasospasm is the cause of these serous retinal detachments. ${ }^{12}$

There is still controversy as to whether the presence of these detachments may influence fetal or maternal prognosis. The choroid vascular insufficiency can lead to lesions in the retinal pigment epithelium, fluid transudation, and focal retinal detachment. ${ }^{12,13}$ The Elschnig's spots, also found in this case, demonstrate areas of focal occlusion of the choriocapillaris 

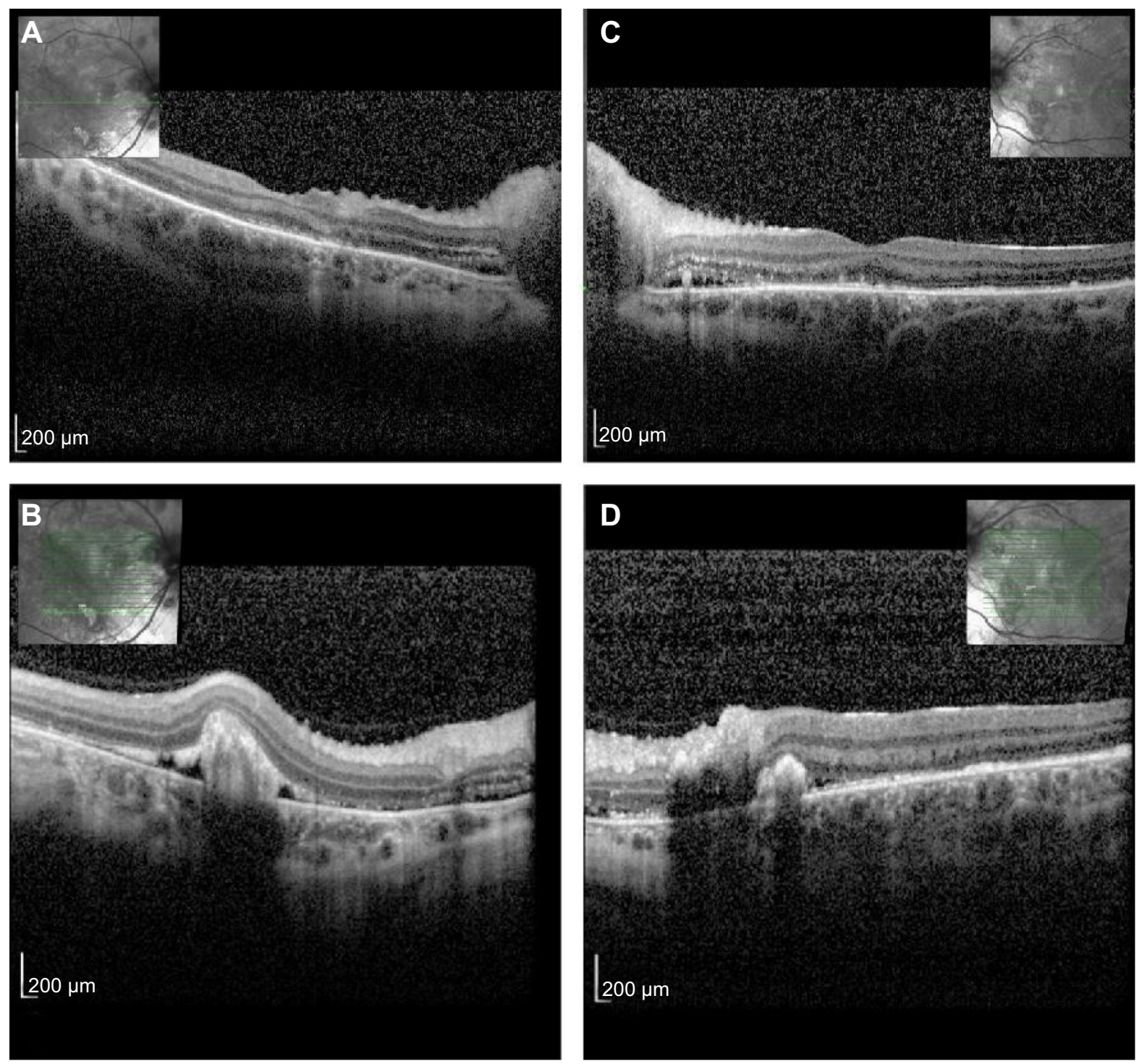

Figure 3 Optical coherence tomography 12 hours post partum.

Notes: Retinal edema, retina serous detachments presenting with a hyperreflective posterior surface of the detached retina, subretinal hyperrreflective lesions corresponding to subretinal transudates, and a thickened peripapillary retinal nerve fiber layer corresponding to optic disc edema. (A) and (B) right eye; (C) and (D) left eye. Insets are infrared fundus image with corresponding OCT.
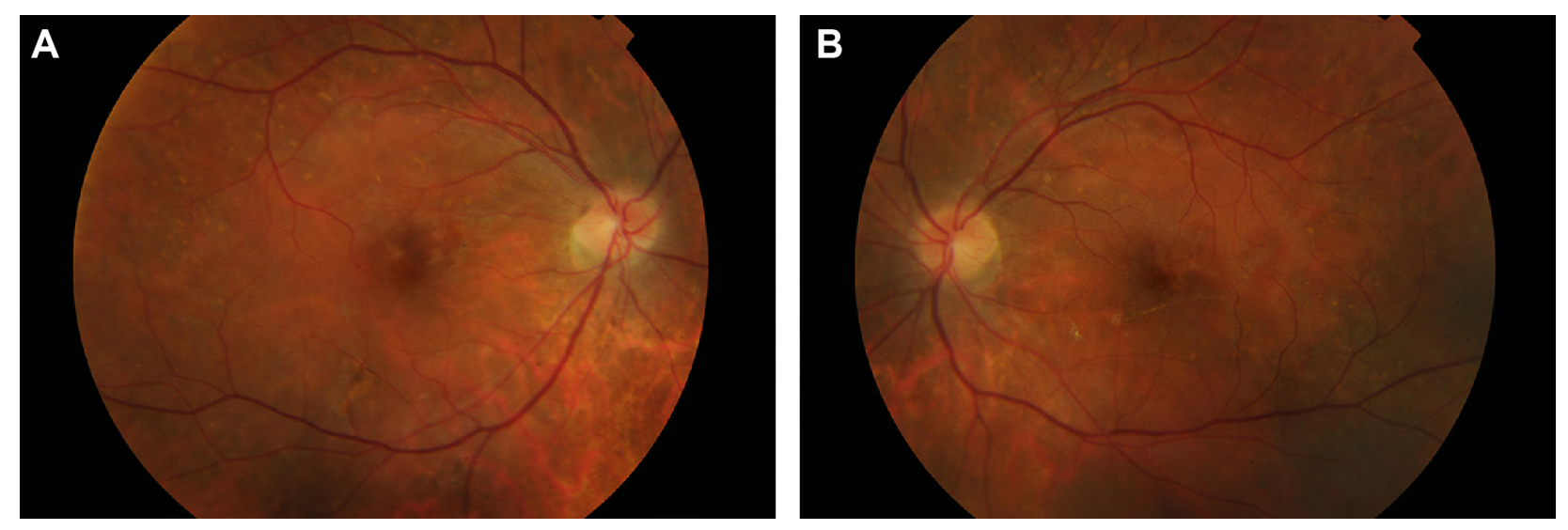

Figure 4 Follow-up examination at 6 months after the acute phase.

Notes: Complete resolution of previous serous detachments, diffuse arteriolar constriction, and multiple yellowish subretinal discoloration spots. (A) right eye; (B) left eye. 
that lead to necrosis and focal atrophy of the retinal pigment epithelium. The optic disc edema seen in this case was caused by local ischemia, as a result of intensive vasospasm of the posterior ciliary arteries supplying its head.

Unusual in this case was the unknown late pregnancy masked by the extreme obesity in a woman who presented with ocular signs of malignant hypertension that included hypertensive retinopathy, choroidopathy and optic neuropathy. This case highlights the need to rule out pre-eclampsia in all women of childbearing age who present with ocular signs of malignant hypertension, even without a known history or external signs of pregnancy, which were masked by morbid obesity in our patient. This case also highlights the critical role ophthalmologists may play in the diagnosis of this potentially devastating disease.

\section{Disclosure}

The authors report no conflicts of interest in this work.

\section{References}

1. Duley L. The global impact of pre-eclampsia and eclampsia. Semin Perinatol. 2009;33(3):130-137.

2. Khan KS, Wojdyla D, Say L, Gulmezoglu AM, Van Look PF. WHO analysis of causes of maternal death: a systematic review. Lancet. 2006;367(9516): 1066-1074.
3. Tranquilli AL, Dekker G, Magee L, et al. The classification, diagnosis and management of the hypertensive disorders of pregnancy: a revised statement from the ISSHP. Pregnancy Hypertens. 2014;4(2): 97-104.

4. Milne F, Redman C, Walker J, et al. The pre-eclampsia community guideline (PRECOG): how to screen for and detect onset of preeclampsia in the community. BMJ. 2005;330(7491):576-580.

5. Tranquilli A, Brown M, Zeeman G, Dekker G, Sibai B. The definition of severe and early-onset preeclampsia. Statements from the International Society for the Study of Hypertension in Pregnancy (ISSHP). Pregnancy Hypertens. 2013;3(1):44-47.

6. [No authors listed]. Report of the National High Blood Pressure Education Program Working Group on High Blood Pressure in Pregnancy. Am J Obstet Gynecol. 2000;183(1):S1-S22.

7. Ober RR. Pregnancy-induced hypertension (pre-clampsia eclampsia). In: Ryan SJ, editor. Retina, Volume 2. St Louis: CV Mosby; 1994:1393-1403.

8. Roos NM, Wiegman MJ, Jansonius NM, Zeeman GG. Visual disturbances in (pre)eclampsia. Obstet Gynecol Surv. 2012;67(4): 242-250.

9. Carreira H, Pereira M, Azevedo A, Lunet N. Trends of BMI and prevalence of overweight and obesity in Portugal (1995-2005): a systematic review. Public Health Nutr. 2012;15(6):972-981.

10. Wagner HP. Arterioles of the retina in toxemia of pregnancy. JAMA. 1933;101(18):1380-1384

11. Schultz JF, O’Brien CS. Retinal changes in hypertensive toxemia of pregnancy: A report of 47 cases. Am J Ophthalmol. 1938;21:767-774.

12. Fastenberg DM, Fetkenhour CL, Choromokos E, Shoch DE. Choroidal vascular changes in toxemia of pregnancy. Am J Ophthalmol. 1980; 89(3):362-368.

13. Saito Y, Tano Y. Retinal pigment epithelial lesions associated with choroidal ischemia in preeclampsia. Retina. 1998;18(2):103-108.
Clinical Ophthalmology

\section{Publish your work in this journal}

Clinical Ophthalmology is an international, peer-reviewed journal covering all subspecialties within ophthalmology. Key topics include: Optometry; Visual science; Pharmacology and drug therapy in eye diseases; Basic Sciences; Primary and Secondary eye care; Patient Safety and Quality of Care Improvements. This journal is indexed on

Submit your manuscript here: http://www.dovepress.com/clinical-ophthalmology-journal

\section{Dovepress}

PubMed Central and CAS, and is the official journal of The Society of Clinical Ophthalmology (SCO). The manuscript management system is completely online and includes a very quick and fair peer-review system, which is all easy to use. Visit http://www.dovepress.com/ testimonials.php to read real quotes from published authors. 